\title{
Sentinel-1 위성영상을 활용한 침수지역판별 및 적용성 평가 Detection of Flood Areas Using Sentinel-1 Satellite Imagery and Evaluation of Its Applicability
}

\author{
박정하* - Dao Duc Anh** . 김수현*** . 김동균**** \\ Park, Jeongha*, Dao, Duc Anh ${ }^{* *}$ Kim, Soohyun ${ }^{* * *}$, and Kim, Dongkyun****
}

\begin{abstract}
The flood detection technique based on synthetic aperture radar (SAR) imagery was assessed. This technique was applied to a flood event in Busan in 2017. Sentinel-1 imagery was acquired, and then different multitemporal change detection methods were applied for SAR data analysis. Observed data were collected from newspapers, social media, and the Korean Fire Protection Association (KFPA). Specifically, flood and non-flood data were collected and used for analysis. As a result of receiver operating characteristic (ROC) curve analysis, the area under the curve (AUC) value was 0.67 , which indicates a generally efficient technique, but it showed lower performance than the random model according to the threshold value. Four of 15 flood sites and a threshold value of 0.02 were selected to compare the flood area between the observed data and the flood maps derived from SAR analysis. As a result, all four flood maps included the observed flood areas, with some overestimation of flood area. A criterion for selecting the optimal threshold was suggested using ROC curve analysis, and the flood map results from this threshold were validated, but follow-up study is required to assess the accuracy numerically.
\end{abstract}

Key words : Synthetic Aperture Radar (SAR), Sentinel-1, ROC, Flood Analysis

\section{요 지}

본 연구에서는 Synthetic Aperture Radar (SAR) 위성영상을 활용하여 침수를 판별하고, 적용성을 평가하고자 한다. 이를 위해 2017년 부산 지역 침수 사상을 분석하였다. Sentinel-1 영상을 사용하였으며, 침수판별기법으로는 침수 전후 시점의 위성영상 이미지 분석 방법을 선택하였다. 관측 자료로는 뉴스 기사와 소셜 미디어 및 화재보험협회 자료를 수집하였다. 특히 침수 지역과 침수가 일어나지 않은 미침수 지역의 자료를 수집하여 분석하였다. Receiver Operating Characteristics (ROC) 곡선 분석을 수행하였으며, 그 결과 Area Under Curve (AUC)는 0.67으로 전반적으로 효율적인 성능을 나타냈으나, 임계값 선택에 따라 무작위 모형보다 비효율적인 결과가 나타났다. 침수 구역 비교를 위해 실제 침수 지역 15 개 중 관측 자료가 충분한 4 개 지역을 선정하였고, $\mathrm{ROC}$ 분석 결과로부터 임계값을 0.02 로 설정하여 비교하였다. 관측 자료에 포함되었던 침수지역은 분석 결과에서 모두 포함하였고, 침수 지역이 다소 과대 추정하는 경향을 보였다. 연구 결과로 ROC 분석을 통한 임계값 선택 기준을 제시하였으며, 침수 지도의 정확성을 확인하였으나, 정량적 평가를 위해 관측 자료가 구체적으로 구축된 사상에 대한 후속연구가 요구된다.

핵심용어 : Synthetic Aperture Radar(SAR), Sentinel-1, ROC, 침수 분석

*정회원, 홍익대학교 토목공학과 박사과정(E-mail: jungha1122@mail.hongik.ac.kr)

Member, Ph.D. Candidate, Department of Civil Engineering, Hongik University

**정회원, 홍익대학교 토목공학과 박사과정

Member, Ph.D. Candidate, Department of Civil Engineering, Hongik University

***정회원, 홍익대학교 토목공학과 박사과정

Member, Ph.D. Candidate, Department of Civil Engineering, Hongik University

****교신저자, 정회원, 홍익대학교 토목공학과 부교수(Tel: +82-70-8221-0058, Fax: +82-2-325-2332, E-mail: kim.dongkyun@hongik.ac.kr)

Corresponding Author, Member, Associate Professor, Department of Civil Engineering, Hongik University 


\section{1. 서 론}

최근 기후변화로 인하여 전 세계적으로 강우의 시공간적 불균형이 심화되고 전례 없는 극한 사상이 발생하고 있다. 이러한 이상기후는 집중호우 및 태풍의 형태로 침수와 같은 도시재난의 대형화 - 복합화를 야기하므로 도시차원에 근본 적인 대응책 마련이 필수적이다.

기상청 주관 2018년 이상기후 보고서(KMA, 2019)에 따르 면 국토교통 분야 이상기후 대응 방안으로 '도시 기후변화 재해취약성 분석 및 활용에 관한 지침' 개정 추진을 통해 재해취약성 분석의 적용대상을 확대하고 있다. 지침 상 침수 지역의 공간적 범위가 구체적인 경우 분석 결과를 토지이용 대책 마련에 적극 활용할 수 있다고 명시되어 있으므로, 구체적이고 정확한 침수지역을 판별하여 침수흔적도를 작 성하는 것이 중요하다.

국내에서는 침수흔적도 작성을 위해 지자체에서 조사 인력을 피해지역에 파견하여 현장조사를 수행하고 있다 (Hwang et al., 2016). 그러나 동시다발적으로 광범위하게 발생하는 침수에 대해서 조사를 담당할 전문 인력 및 예산이 부족한 실정이며(Lee et al., 2006), 피해조사가 부정확할 가능 성이 존재한다(NIDP, 2008). 이와 더불어 침수흔적도 자료는 피해연도의 이듬해에 제공되므로 침수자료의 즉각적인 접근 및 차후 대응이 불가하다(Goo et al., 2011; Lim et al., 2016).

인공위성을 활용한 원격탐사 기법은 광범위하고 다양한 재난에 대한 분석 자료를 효율적이고 저비용으로 얻을 수 있기 때문에 침수흔적도 작성 기법의 대안으로 제시되고 있다(Notti et al., 2018). 홍수- 침수 등 수재해는 악천후를 동반하기 때문에 인공위성 자료 중 기상의 영향을 적게 받는 합성개구레이더(Synthetic Aperture Radar; SAR)영상의 활용 성이 높아지고 있다.

SAR 위성자료는 인공위성에서 자체 방출한 마이크로파가 이미지 표면에서 반사되어 돌아오는 후방 산란 값(backscatter) 을 통해 자료가 생성된다. 이러한 반사 신호에 강약에 영향을 미치는 요인은 레이더 자료 특성(관측 방향, 주파수, 파장 등), 이미지 표면 특성(거칠기, 수분 등), 환경 및 기상 요인(온 도 비, 바람 등)이 있다. 그중에서 SAR의 마이크로파 신호는 표면 거칠기에 따라 유입되는 레이더 후방 산란 값이 크게 변화하는데, 특히 지표면과 수표면의 후방 산란 값은 큰 차이를 보인다. 이때, 수체의 부드러운 표면은 레이더의 반사면으로 작용하여 낮은 후방 산란 값을 가지며, 위성 영상에서 검은 색으로 표현되어 지면과 구분된다.

이러한 SAR 영상의 특성을 통하여 다양한 침수 지역 판별 기법이 개발되었다. 침수지역판별 방법으로는 대표적 으로 단순 육안 판독(Oberstadler et al., 1997), 감독 분류 (Townsend, 2002), 레이더 후방 산란 값의 히스토그램 임계값 산정(Schumann et al., 2014), 여러 시점의 다중 위성영상 이미 지의 비교 방법(Shin et al., 2012; Hwang et al., 2016) 등이
있다(Perrou et al., 2018).

$\mathrm{SAR}$ 를 활용하여 침수 지역을 분석한 국내 사례로는 Nam (2004)가 RADARSAT SAR 영상을 활용하여 낙동강 유역에 발생한 집중호우로 인한 침수지역을 다중시점 영상을 비교 하여 침수지역을 구분하였고, Landsat TM 자료를 이용하여 토지 이용별 침수면적을 계산하였다. Oh (2018)에서는 미국 휴스턴 지역에 허리케인 하비로 발생한 침수를 Sentinel-1와 임계값추출방법을 통해 분석하였고, 검증 자료로 드론 촬영 자료를 활용하여 토지상태에 따른 분석방법의 정확도를 제시 하였다. Kim et al. (2007)에서는 RADARSAT SAR 자료를 1999년 삽교천 유역 홍수 분석에 적용하였고, 이 결과와 수리분석에 의한 결과를 침수실적도와 비교하여 SAR 침수분 석자료가 내수배제 불량에 의한 침수구역 산정에 더욱 효율 적이라는 결론을 얻었다.

국외 사례로는 Brivio et al. (2002)가 1994년 이탈리아 Tanaro 강에 발생한 홍수를 ERS SAR 위성영상과 지형자료를 활용하여 홍수범위를 추정하였고 실측자료와 비교결과 면적 의 96.7\%가 일치하였다. Perrou et al. (2018)는 Sentinel-1 A 자료와 임계값 분류법 및 다중시점 영상 비교 방법을 통해 4 개 국가(불가리아, 그리스, 마케도니아, 세르비아)를 포함하 는 Strymon/Struma 유역에서 침수지역 분석 및 침수발생원인 을 규명하였다. Notti et al. (2018)은 MODIS, Proba-V, Landsat, Sentinel-2, Sentinel-1과 같은 개방 위성 자료를 이용하여 스페 인과 이탈리아에서 발생한 침수에 대하여 판별하였으며, 영향 요인을 분석하여 정확도 $5 \%$ 부터 $95 \%$ 까지 결과를 도출했다.

위와 같은 분석을 적용하기 위해서 2017년 9월 11일 발생 한 부산 지역 집중호우 - 침수 사상에 대하여 분석을 수행하 였다. 분석 방법으로는 침수 전후 시점 위성영상 분석 방법을 선택하였으며, 분석 자료로는 European Space Agency (ESA) 의 Sentinel- 1 을 선택하였다. 이 기간의 침수는 단기간에 동시다발적으로 발생하여 침수흔적도가 완벽하게 구축되지 않아 해당 기간 뉴스 기사와 소셜 미디어 및 화재보험협회 (Korean Fire Protection Association, KFPA) 자료를 검증자 료로 활용하였고, 마지막으로 수신자 조작 특성(Receiver Operating Characteristics, ROC) 곡선 분석을 통해 침수자료 의 적용가능성을 평가하였다.

\section{2. 연구 방법}

\section{1 연구대상지}

본 연구의 연구대상지는 부산 지역으로 설정하였다(Fig. 1). 부산은 $30 \%$ 이상의 높은 불투수면적 비율(ME, 2013)과 경사가 급한 지형이 많아 집중호우 발생 시 저지대 침수가 빈번히 일어난다. 부산은 2017년 기준으로 이전 10 년간 풍수해에 의한 피해액이 1,740 억원으로 주요도시 중 최대 피해를 입었으며, 평균 2년에 한 번의 대규모 침수로 막대한 경제적-사회적 피해에 노출되고 있다(Kim, 2017). 


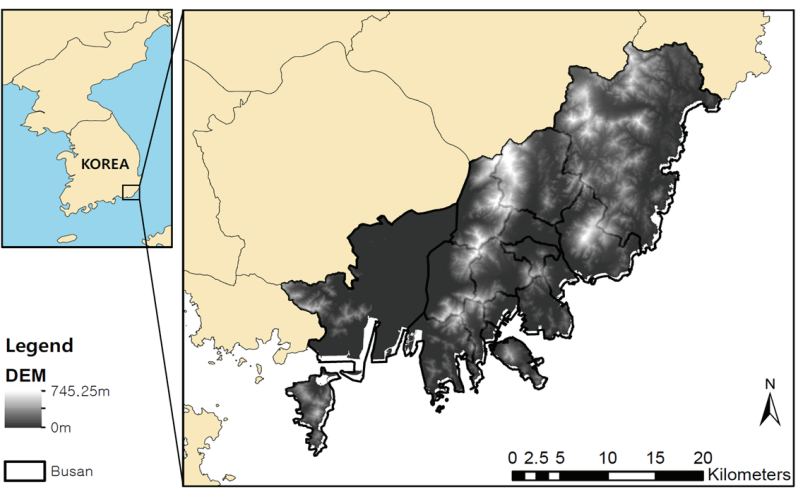

Fig. 1. Location of Study Area

분석을 적용한 침수 사상은 2017년 9월 11일에 부산 전역 에 걸친 집중호우로 인한 침수이며, 이 때 부산 관측소(관측 소번호: 159)에서는 일강수량 $264.1 \mathrm{~mm}$ 를 기록하였다. 이뿐 만 아니라 부산의 15 개 관측소 중 8 개 관측소에서 100 년 빈도 이상의 강우강도가 발생하여(Kim, 2017), 약 14억원의 총 피해액을 기록하였다(MOIS, 2018).

\section{2 위성영상 DATA}

위성영상으로는 ESA에서 제공하는 Sentinel-1 SAR위성 영상을 선택하였다. Sentinel-1 자료는 ESA 웹사이트(https:// scihub.copernicus.eu/dhus/\#/home)에서 무료로 접근할 수 있 으며, 위성자료 분석 소프트웨어(SNAP)와 Toolbox도 제공 하고 있다. Sentinel-1는 위성에서 방출된 C-band 레이더 신호가 표면에 반사되어 돌아오는 값을 측정하는 active sensor로 구성되어 있으며, 기상 조건에 관계없이 영상을 구성할 수 있다. 연구 대상 침수 시점 전후의 Sentinel-1 영상을 수집하였으며(Fig. 2), 영상의 제원은 Table 1에 기술 하였다.

\section{3 침수지역 산정 방법}

본 연구의 자료처리과정은 Fig. 3 과 같다. 크게 인공위성 영상처리, 침수 및 미침수 관측 자료 수집 그리고 적용성

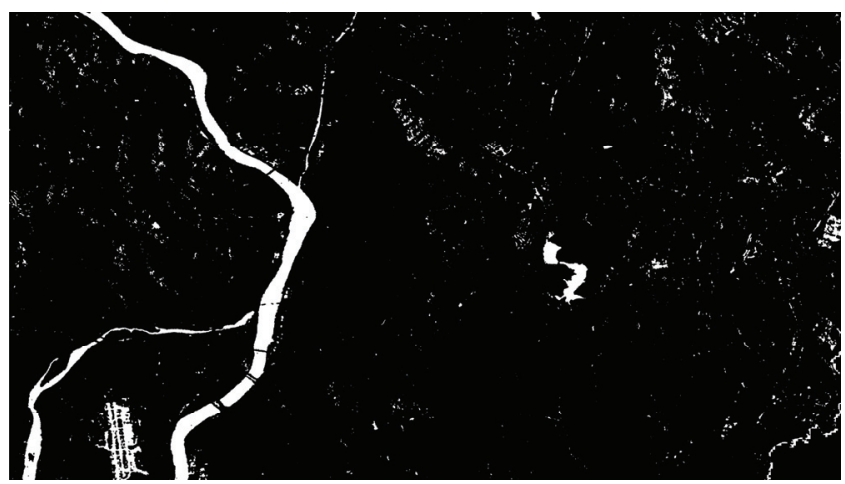

(a) Before Flood
분석 과정으로 구성되어있다.

Table 1. Sentinel-1 Product Data

\begin{tabular}{c|c|c}
\hline $\begin{array}{c}\text { Sentinel-1 } \\
\text { Characteristics }\end{array}$ & Before & After \\
\hline Date(KST) & '17.08.30. 18:23 & '17.09.11. 18:23 \\
\hline MISSION & Sentinel-1A (ascending) \\
\hline Sensor Type & C-band SAR \\
\hline Product Type & GRD \\
\hline Acquisition Mode & IW \\
\hline Resolution & 10 m (approximate) \\
\hline Revisit period & 12 days \\
\hline Polarization Option & Dual (VV, VH)
\end{tabular}

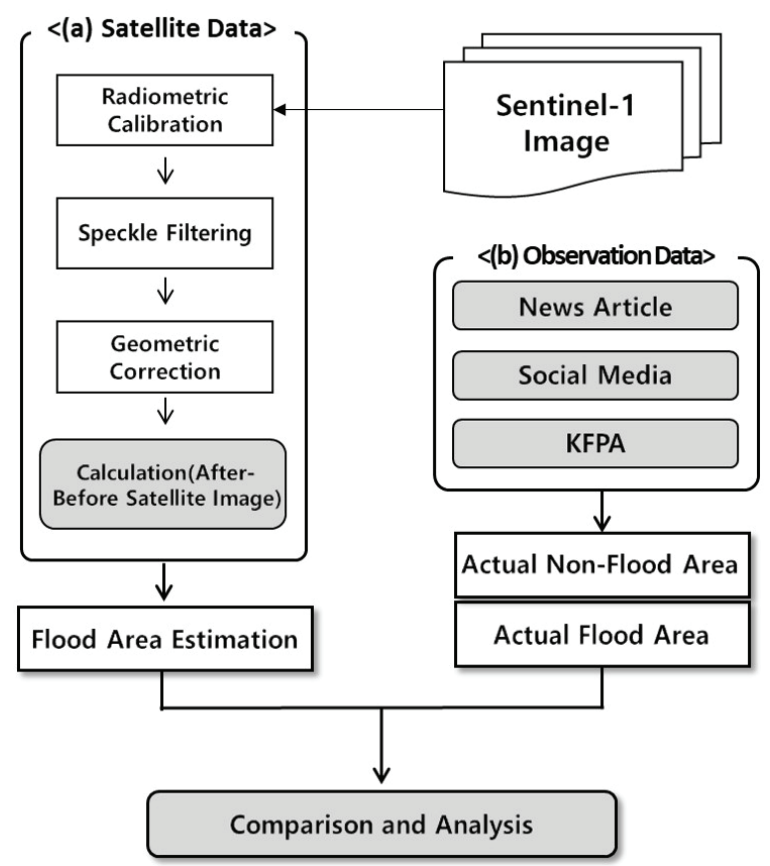

Fig. 3. Flow Chart of Data Processing

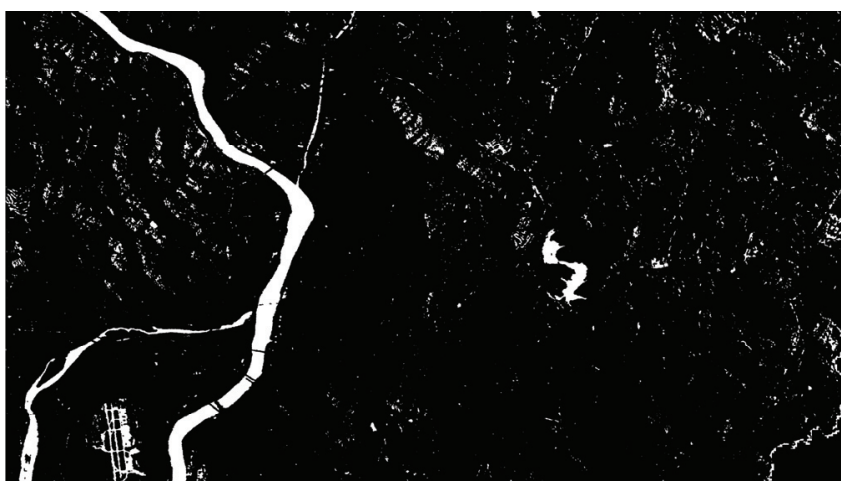

(b) After Flood

Fig. 2. Satellite Images 


\subsection{1 인공위성 영상처리}

Fig. 3a은 위성자료 처리과정을 나타낸다. Sentinel-1은 후방 산란 값으로 영상이 표출되고, 이에 따라 스페클 노이즈 (Speckle Noise)를 동반한다. 또한 촬영 각도로 인한 오차를 보정하는 처리과정을 거쳐야한다(Brivio et al., 2010). 이와 같은 전처리 과정은 $\mathrm{ESA}$ 에서 제공하는 위성자료 분석 소프 트웨어 SNAP을 이용하여 처리하였다.

Sentinel-1의 원자료는 촬영범위가 광범위하여 세부영역 을 설정하여 추출하였다. 그다음, 오차가 포함된 전자기파를 보정하는 방사보정을 수행하고, 노이즈를 매끄럽게 처리하 는 스페클 필터링을 수행하였다. 스페클 필터는 Gaussian 분포에 맞추어 수치값을 평균치로 보정하는 Lee sigma 필터 를 사용하였다(Lee, 1983). 이때, 편광 옵션으로 침수지역 판별에 용이한 VH를 선택하였다(Ezzine et al., 2018). 최종적 으로 지형 왜곡 및 촬영 각도에 따른 오차를 보정하는 지형보 정을 진행하였다. 전처리가 완료된 영상은 침수 전과 후의 차이를 통해 각 격자 값이 -1 부터 1 사이 값을 가지며, 해당 범위 사이의 임계값을 설정하여 침수판별기준을 세울 수 있다. 일반적으로 전후 영상에서 지표면 특성 변화가 없는 경우 0 에 가까운 값을 가지며, 전후 영상에서 지표면이 반사 신호가 큰 마른 표면에서 반사 신호가 작은 수표면으로 전환될 시 0 이상의 값을 나타내게 된다.

\subsection{2 침수 및 미침수 관측 자료 수집}

먼저 해당 기간에 대해서 침수가 발생한 그리고 발생하지 않은 현장 사진 자료를 각각 침수 및 미침수 관측 자료라고 정의하였다. SAR 위성영상을 활용한 침수판별기법의 정확도 검증을 위해 침수 관측 자료를 뉴스 기사 및 화재보험협회의 사고현장 자료(https://ucis.kfpa.or.kr/mapindex.do)를 통해 수 집하였다. 한편, $\mathrm{ROC}$ 곡선을 통해 판별기법의 적용성을 판단 함에 있어서 실제 침수 지역을 인공위성을 통해 얼마나 판별해 낼 수 있는지를 나타내는 척도인 민감도(Sensitivity) 뿐만 아니라, 실제 침수가 일어나지 않은 지역을 침수가 일어나지 않았다고 판별해낼 수 있는 척도인 특이도(Specificity)를 고려해야한다. 그 과정 중 가장 중요한 것은 미침수 지역에 대한 관측 자료의 신뢰도이므로 본 연구에서는 침수 신고나 침수 자료가 없는 곳을 미침수 지역으로 간주하지 않고, 사진으로 미침수 지역을 확인할 수 있는 자료를 뉴스 기사 및 소셜 미디어를 통해 수집하였고, 결과 분석에 활용하였다. Fig. 4에서 노란색 점은 침수 발생 지점, 초록색 점은 미침수 지점을 나타내며 각 각 15 개, 9 개로 구성되었다. 지점에 대한 자세한 위치구분 및 출처는 Appendix에 수록하였다.

\subsection{3 적용성 분석}

Sentinel-1 기반 침수판별기법의 적용성을 평가하기 위해 $\mathrm{ROC}$ 곡선 분석을 수행하였다. ROC 곡선 분석에서는 먼저 사상이 오직 2가지(침수, 미침수)로 분류되는 문제에 적용될
수 있으며, 반드시 신뢰할 수 있는 실제 결과가 필요하다. 분류 기준 모형(Sentinel-1 기반 침수판별기법)에 따라 Table 2와 같이 오차행렬(Confusion matrix)을 작성할 수 있으며, 이는 실제 계층과 예측 계층으로 나누어져 두 계층의 차이를 표현한다. Positive를 1, Negative를 0 으로 설정했을 때 실제 1 의 값을 가지는 데이터에 대해 분류 모델이 1 로 분류한 비율을 $\mathrm{T}_{\mathrm{P}}, 0$ 으로 잘못 분류한 비율을 $\mathrm{F}_{\mathrm{N}}$ 라고 하며, 실제 0 의 값을 가지는 데이터에 대해 0 으로 정확히 분류한 비율을 $\mathrm{T}_{\mathrm{N}}, 1$ 로 잘못 분류한 비율을 $\mathrm{F}_{\mathrm{P}}$ 라고 한다.

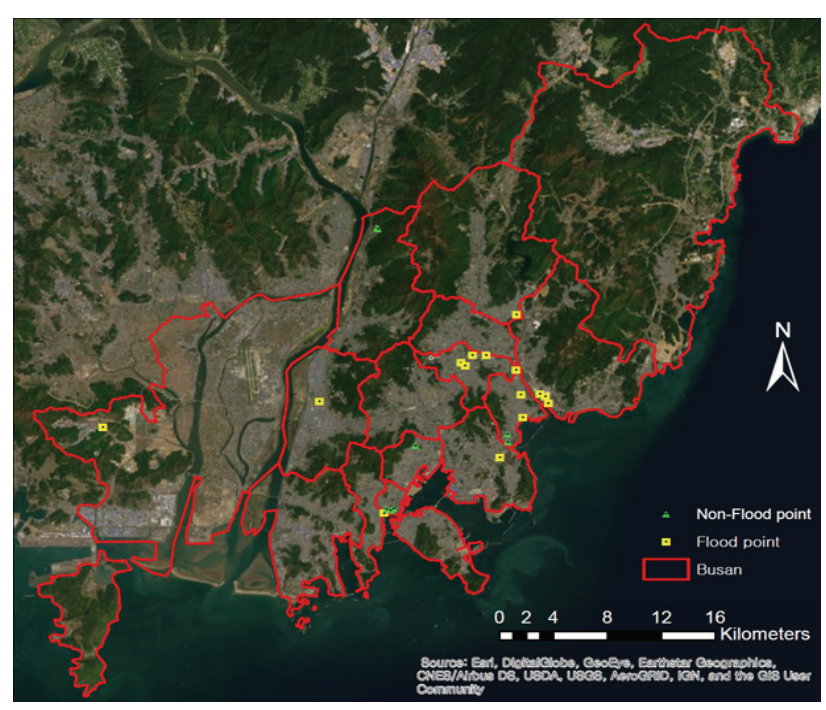

Fig. 4. Flood and Non-Flood Sites (Detailed in Appendix)

Table 2. Confusion Matrix

\begin{tabular}{|c|c|c|c|}
\hline \multirow{2}{*}{\multicolumn{2}{|c|}{$\begin{array}{l}\text { Sentinel-1 Flood } \\
\text { Analysis Method }\end{array}$}} & \multicolumn{2}{|c|}{ Actual class } \\
\hline & & Positives & Negatives \\
\hline \multirow{2}{*}{$\begin{array}{l}\text { Predicted } \\
\text { class }\end{array}$} & Positives & $\mathrm{T}_{\mathrm{P}}$ & $F_{P}$ \\
\hline & Negatives & $\mathrm{F}_{\mathrm{N}}$ & $\mathrm{T}_{\mathrm{N}}$ \\
\hline
\end{tabular}

분류 모형의 적용성을 분석시 고려해야할 두 가지 항목은 실제 1 의 값을 갖는 데이터를 1 로 분류하는 비율인 민감도 (Sensitivity)와 실제 0 의 값을 갖는 데이터를 0 으로 분류하는 비율인 특이도(Specificity)이다. 민감도는 $\mathrm{T}_{\mathrm{P}} /\left(\mathrm{T}_{\mathrm{P}}+\mathrm{F}_{\mathrm{N}}\right)$ 로 표 현되며, 특이도는 $\mathrm{T}_{\mathrm{N}} /\left(\mathrm{F}_{\mathrm{P}}+\mathrm{T}_{\mathrm{N}}\right)$ 으로 표현된다. 무작위 분류 모형에서는 이 두 수치가 반비례하는 경향이 있으므로, 이를 모두 고려한 분류 모형 평가 지표를 활용해야한다. 이를 위해 ROC 곡선이 Fig. 5 와 같이 제시되었다. ROC 곡선의 $\mathrm{x}$ 축은 특이도의 반대값인 ' 1 -특이도', $\mathrm{y}$ 축은 '민감도'로 이루 어져 있으며, 모형 평가 지표는 ROC 곡선의 밑면적(Area Under the ROC Curve; AUC)이다. Fig. 5의 점선으로 나타낸 참조 선은 무작위 분류 모형으로 이 직선의 $\mathrm{AUC}$ 인 0.5 보다 큰 값, 즉 위로 더욱 많이 떨어진 곡선을 나타낼수록 효율적인 모형으로 평가된다. 본 연구에서는 처리된 SAR 영상에서 임계값을 -1 부터 1 까지 0.1 씩 증가시키며 그 때 산정된 특이 
도와 민감도에 따라 ROC 곡선을 도출하였다.

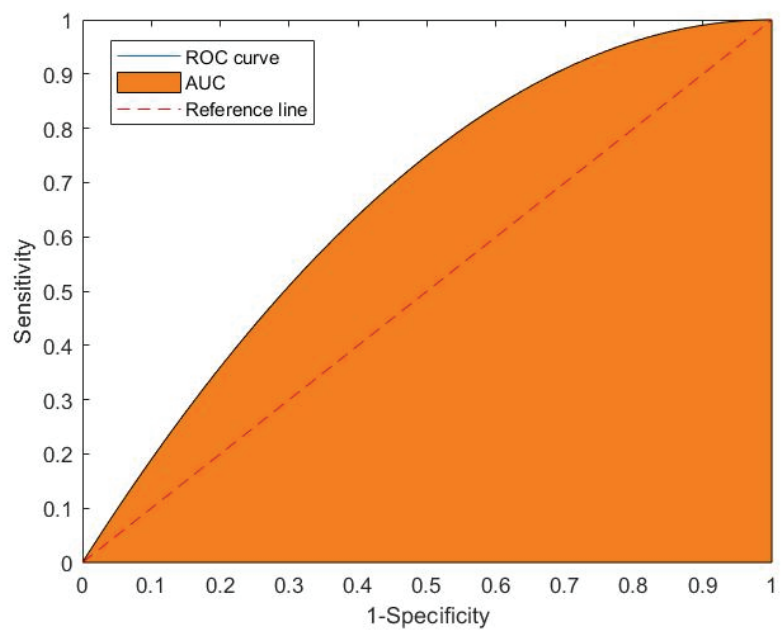

Fig. 5. Concept of ROC Curve and AUC

\section{3. 연구 결과}

\section{$3.1 \mathrm{ROC}$ 곡선 분석}

$\mathrm{SAR}$ 위성영상을 통한 침수판별기법의 적용성을 판단하 기 위해 ROC 곡선 분석을 실시하였다. 여기서 '침수’를 Positive, ‘미침수’를 Negative로 설정하여 분석하였으므로 민감도는 실제 침수 지역을 분석 기법을 통해 침수 지역으로 잘 분류해내는 지표이고, 특이도는 실제 미침수 지역을 제대 로 분류해내는 지표라고 할 수 있다. 실제 침수 지역 15 개 지점, 미침수 지역 9 개 지점을 대상으로 임계값을 -1 부터 1 까지 변화시키며 침수, 미침수를 판별하였으며, 그 결과 $\mathrm{ROC}$ 곡선은 Fig. 6 과 같다. Fig. 6에서 각 점들은 임계값이 변함에 따라 민감도나 특이도가 변하는 지점을 나타내며, 그 때의 임계값을 색상으로 나타내었다. 그림의 컬러바는 유효한 임계값 범위로 축소하여 대비시켰다.

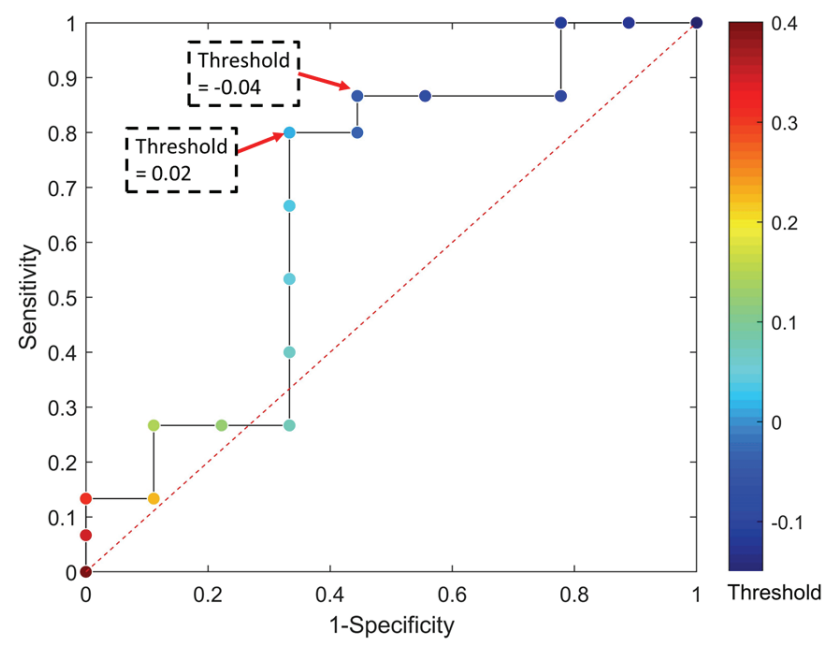

Fig. 6. Result of ROC Curve
먼저 AUC 값은 0.67로 나타나 전반적으로 효율적인 판별 기법으로 판단할 수 있다. 그러나 reference line보다 아래에 찍힌 점에서 볼 수 있듯이 임계값 설정에 따라 무작위 모형보 다 침수 판별 효율이 더 낮아질 수 있다. 따라서 임계값을 잘 선택하는 것이 중요하며, 사용자의 목적에 따라 민감도 또는 특이도를 증가시키는 임계값을 선택할 수 있다. 민감도 와 특이도는 반비례할 수 있지만 위 결과에서는 특히 임계값 -0.04 이하 0.02 이상의 범위에서는 민감도와 특이도가 각 각 상대 지표의 증가량에 비해 큰 폭으로 감소하는 것을 확인할 수 있었다. 본 연구에서는 보수적인 관점으로 임계값을 선정 하여 약 $80 \%$ 의 민감도를 가지는 임계값 0.02 로 실제 침수 지역 대상 침수 지도를 작성하여 관측 자료와 비교하였다.

\section{2 침수 구역 비교}

침수 관측 자료로 활용한 현장 사진은 침수 지역 중 일부분 만 알 수 있기 때문에 침수 면적이나 침수심 비교와 같은 정량적 분석에는 한계가 있다. 따라서 본 연구에서는 정성적 분석에 초점을 맞추고, 추후 후속 연구에서 침수 지역 및 면적이 침수흔적도에 정밀하게 구축된 사상에 대하여 추가 적으로 분석해볼 수 있을 것이다.

Fig. 7 은 침수 발생 지점 15 개 지점에서 비교적 관측 자료의 공간적 범위가 넓게 촬영된 4 개 지점을 선정하여 관측 자료와 연구 분석 결과를 비교한 그림이다. 임계값을 보수적으로 선정한 만큼 침수 지역이 실제보다 다소 과대 산정되는 경향 을 보였으나 4지점 모두 관측 자료에서 보이는 침수지역을 대부분 포함하는 결과를 나타냈다. 또한 주변에 높은 건물이 위치한 Figs. 7(c), (d)에서 오차가 상대적으로 크게 나타나는 데, 이는 장애물에 의해 반사되어 SAR의 신호가 과대 추정된 것으로 해석된다. 이를 통해 ROC 곡선 분석 결과로 해당 지점 격자 침수여부를 판별하고, 분석목적에 최적인 임계값 을 산정하여 침수 지역을 추정할 수 있다는 결과를 얻었다.

\section{4. 결 론}

본 연구에서는 기상 조건에 의한 영향이 상대적으로 적은 SAR 위성영상을 활용하여 침수를 판별하고, 판별기법의 적용성을 분석하고자하였다. 이를 위해 2017년 9월 11일 발생한 부산 지역 집중호우·침수 사상을 대상으로 선정하 여 수행하였다. 인공위성영상 기반 침수판별기법으로는 침 수 전후 시점의 위성영상 이미지를 분석 방법을 선택하였으 며, 분석 대상 자료로는 European Space Agency (ESA)의 Sentinel-1로 설정하였다. 이 기간의 침수는 단기간에 동시다 발적으로 발생하여 침수흔적도가 완벽하게 구축되지 않아 해당 기간 뉴스 기사와 소셜 미디어 및 화재보험협회(Korean Fire Protection Association, KFPA) 자료를 검증자료로 활용하 였다. 특히 침수 지역뿐만 아니라 침수가 일어나지 않은 미침 수 지역에 대한 관측 자료를 수집하여 분석에 활용하였다. 


\section{(a)}

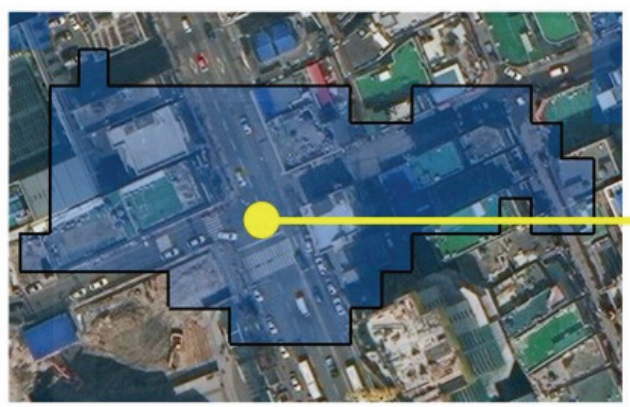

(b)

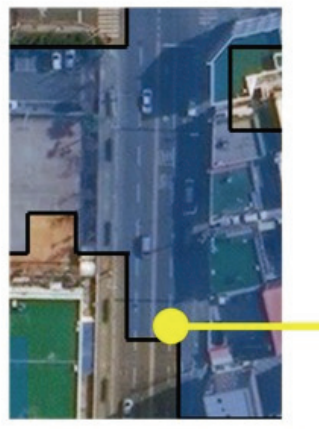

(c)

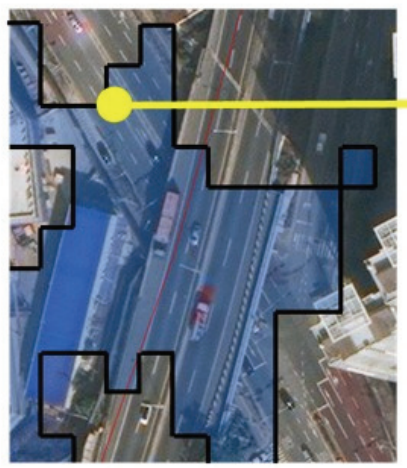

(d)
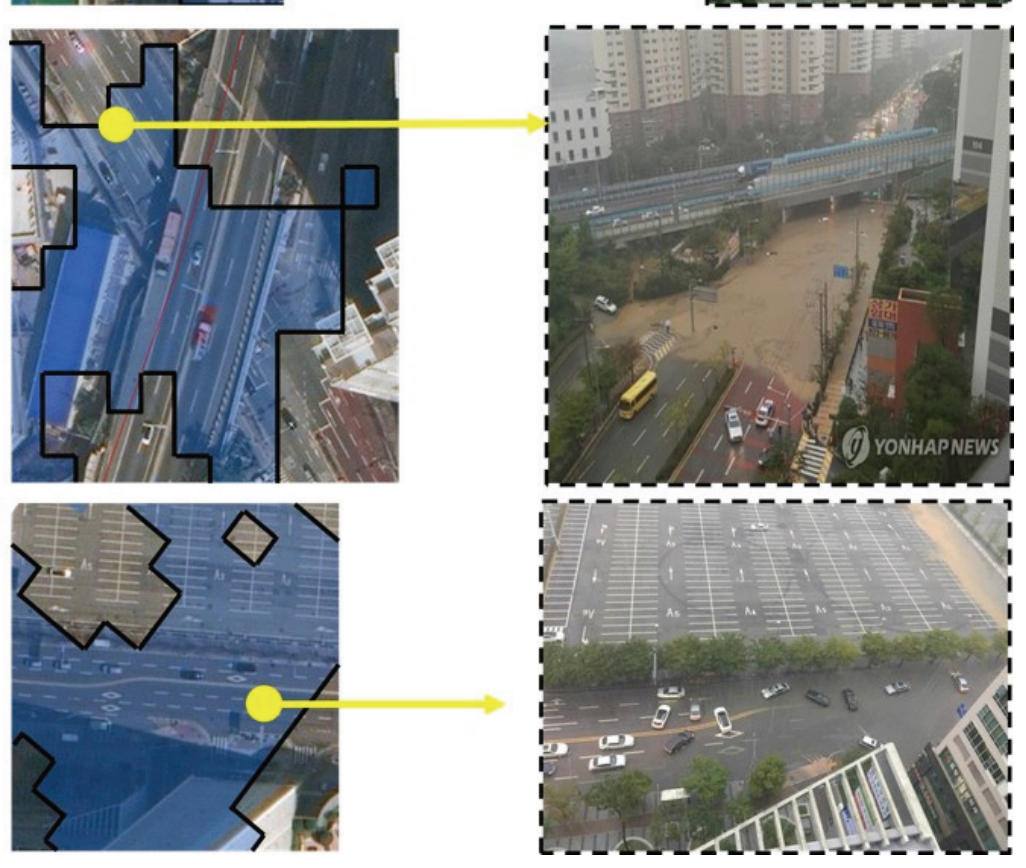

Fig. 7. Comparison of Flood Area Between Observed Data and Flood Map Derived by SAR Imageries. Locations and Data Source Information are Included in Appendix. Flood Sites of (a) through (d) correspond to Site No. 2, 5, 7, and 9, respectively

먼저 침수판별기법에 대한 $\mathrm{ROC}$ 곡선 분석 결과 $\mathrm{AUC}$ 는 0.67 으로 전반적으로 효율적인 성능을 나타냈으나, 임계값 선택에 따라 무작위 모형보다 비효율적인 결과가 나타날 수 있음을 확인하였다. 실제 침수 지역의 침수 구역 비교를 위해 임계값을 0.02 로 다소 보수적으로 설정하여 관측 자료 와 비교하였다. 실제 침수 지역 15 개 지점 중 관측 자료가 넓은 공간적 범위를 포함하는 4지점에 대하여 비교하였으며, 정량적인 분석은 불가능하여 육안으로 확인되는 지역까지 비교하였다. 비교 결과 관측 자료에 포함되었던 침수 지역은
분석 결과에서 모두 포함하는 것으로 확인되었고, 임계값을 보수적으로 설정한 만큼 분석된 침수 지역이 다소 과대추정 하는 경향을 보였다.

본 연구에서는 침수판별기법의 임계값 산정시 실제 미침 수 지역을 활용해 정확도를 높였다는 점에서 침수 지역만 관측 자료를 구축한 기존 연구와 구분된다. 연구 결과로 $\mathrm{ROC}$ 곡선 분석을 통한 최적 임계값 선택 기준 제시를 하였으 며, 이를 통해 분석한 침수 지도의 활용성을 판단하였다. 다만, 관측 자료에 한계로 침수 지도의 정량적 분석이 불가하 
였기 때문에 후속 연구에서는 침수 면적 등 관측 자료가 잘 구축된 사상에 대하여 이를 검증하여 SAR 위성영상을 활용한 침수판별기법의 활용성을 더 구체화하여 제시할 수 있을 것이다.

\section{감사의 글}

본 연구는 행정안전부 재난예측및저감연구개발사업의 지원을 받아 수행된 연구입니다(MOIS-재난-2015-05).

\section{References}

Brivio, P.A., Colombo, R., Maggi, M., and Tomasoni, R. (2002). Integration of remote sensing data and GIS for accurate mapping of flooded areas. International Journal of Remote Sensing, Vol. 23, No. 3, pp. 429-441.

Ezzine, A., Darragi, F., Rajhi, H., and Ghatassi, A. (2018). Evaluation of Sentinel-1 data for flood mapping in the upstream of Sidi Salem dam (Northern Tunisia). Arabian Journal of Geosciences, Vol. 11, No. 8, 170. doi:10.1007/s12517-018-3505-7

Goo, S.H., Kim, S.S., Park, Y.J., and Choi, J.W. (2011). Accuracy improvement for building inundation trace map using accurate DEM data and flood damage information. Journal of Korean Society for Geospatial Information System, Vol. 19, No. 4, pp. 91-99.

Hwang, S.H., Kim, K.H., Lee, G.H., and Lee, M.R. (2016). A study on the development of automated damage estimation system using high resolution satellite imagery. J. Korean Soc. Hazard Mitig., Vol. 16, No. 2, pp. 161-172.

Kim, K.T., Kim, J.H., Park, J.S., and Byun, I.K. (2007). Analysis of flood inundation using WMS and RADARSAT SAR image. Journal of the Korean Association of Geographic Information Studies, Vol. 10, No. 3, pp. 1-12.

Kim, K.W. (2017). Maximization of urban drainage system capacity to reduce flood damage and development of low impact and introduction of flood map database. Busan Development Forum, Vol. 168, pp. 102-108.

Korea Meteorological Administration (KMA). (2019). 2018 Abnormal climate report.

Lee, J.S. (1983). Digital image smoothing and the sigma filter. Computer Vision, Graphics, and Image Processing, Vol. 24, No. 2, pp. 255-269.

Lee, M.S., Park, G.A., and Kim, S.J. (2006). A study on the extraction of flood inundated scar of rural small stream area using RADARSAT SAR images. Journal of Korea Water Resources Association, Vol. 39, No. 11, pp. 969-976.

Lim, H.T., Ahn, S.W., Kim, J.S., Park, S.Y., and Kim, Y.S. (2016). A study on the application of unmanned aerial vehicle for improvement method of the making inundation trace map. J. Korean Soc. Hazard Mitig., Vol. 16, No. 2, pp. 223-231.

Ministry of Environment (ME). (2013). Nationwide impervious area survey and improvement plan.

Ministry of the Interior and Safety (MOIS). (2018). Statistical yearbook of natural disaster 2017.

Nam, B.H. (2004). Analysis of flood inundated area using rader imagery. Master's thesis, University of Ulsan.

National Institute for Disaster Prevention (NIDP). (2008). Development of automated damage investigation system using spatial images.

Notti, D., Giordan, D., Caló, F., Pepe, A., Zucca, F., and Galve, J. (2018). Potential and limitations of open satellite data for flood mapping. Remote Sensing, Vol. 10, No. 11, 1673. doi:10.3390/rs10111673

Oberstadler, R., Hönsch, H., and Huth, D. (1997). Assessment of the mapping capabilities of ERS-1 SAR data for flood mapping: A case study in Germany. Hydrological Processes, Vol. 11, No. 10, pp. 1415-1425.

Oh, M.K. (2018). Evaluation of applicability of threshold filtering method using the Sentinel-1 data. Master's thesis, Hongik University.

Perrou, T., Garioud, A., and Parcharidis, I. (2018). Use of Sentinel-1 imagery for flood management in a reservoir-regulated river basin. Frontiers of Earth Science, Vol. 12, No. 3, pp. 506-520.

Schumann, G.P., Vernieuwe, H., De Baets, B., and Verhoest, N.E.C. (2014). ROC-based calibration of flood inundation models. Hydrological Processes, Vol. 28, No. 22, pp. 5495-5502.

Shin, H.J., Chae, H.S., Hwang, E.H., and Park, J.Y. (2012). A study of informationization technique for detecting flood inundation area using RS. Journal of the Korean Association of Geographic Information Studies, Vol. 15, No. 1, pp. 172-183.

Townsend, P.A. (2002). Relationships between forest structure and the detection of flood inundation in forested wetlands using C-band SAR. International Journal of Remote Sensing, Vol. 23, No. 3, pp. 443-460.

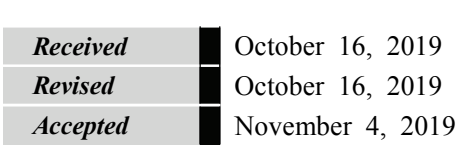




\section{Appendix. Information of Observed Data}

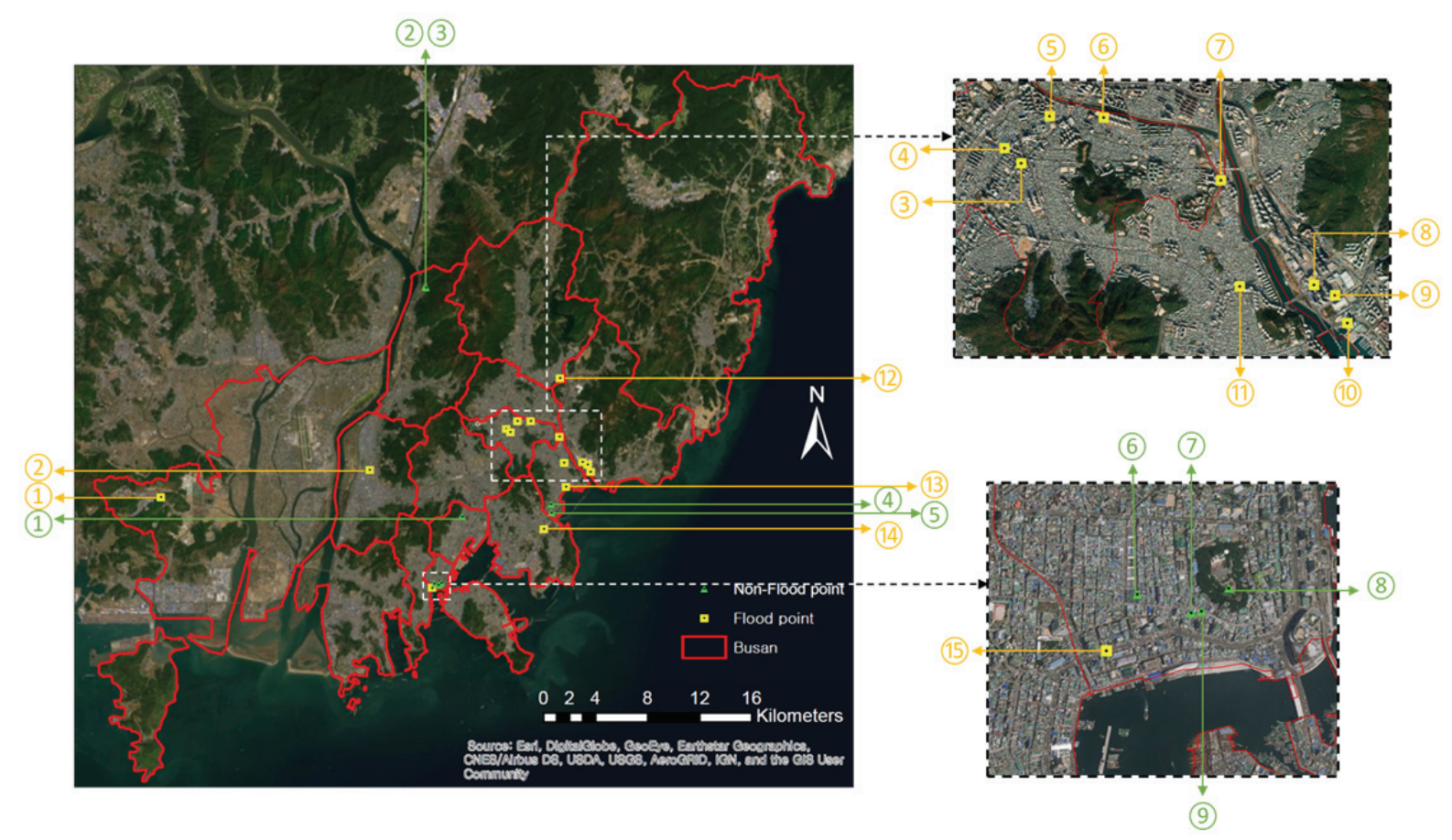

Fig. 8. Detailed Information of Flood and Non-Flood Sites

Table 3. Information of Flood Sites

\begin{tabular}{|c|c|c|}
\hline No. & Address & Source \\
\hline 1 & 1100-3, Noksan-dong, Gangseo-gu, Busan & $\begin{array}{l}\text { http://news.naver.com } / \text { main } / \text { read.nhn?mode=LSD\&mid=sec\&oid=001\& } \\
\text { aid=0009535772\&sid } 1=001 \& 1 \text { from=twitter }\end{array}$ \\
\hline 2 & 272-19 Gwaebeop-dong, Sasang-gu, Busan & https://twitter.com/_haeinge_/status/907016563894607872/photo/1 \\
\hline 3 & 1242-12 Yeonsan-dong, Yeonje-gu, Busan & https://ucis.kfpa.or.kr/mapindex.do \\
\hline 4 & 1143-1 Yeonsan-dong, Yeonje-gu, Busan & http://news.tf.co.kr/read/life/1701805.htm \\
\hline 5 & 581-2 Yeonsan-dong, Yeonje-gu, Busan & http://www.busan.com/view/busan/view.php?code=20170911000037 \\
\hline 6 & 349-11 Yeonsan 8-dong, Yeonje-gu, Busan & $\begin{array}{l}\text { http://news.g-enews.com/view.php?ud=2017091109462044890cc1df6c } \\
\text { ba_1\&md=20170911101316_F }\end{array}$ \\
\hline 7 & 2175-7 Yeonsan-dong, Yeonje-gu, Busan & $\begin{array}{l}\text { http://news.naver.com } / \text { main } / \text { read.nhn?mode }=\text { LSD\&mid }=\text { sec\&oid }=001 \& \\
\text { aid }=0009535772 \& \text { sid } 1=001 \& 1 \text { from }=\text { twitter }\end{array}$ \\
\hline 8 & 1524 U 2-dong, Haeundae, Busan & https://www.yna.co.kr/view/AKR20170913159900051 \\
\hline 9 & 1500 U-dong, Haeundae, Busan & http://www.busan.com/view/busan/view.php?code=20170911000055 \\
\hline 10 & 1398-2 U 3-dong, Haeundae, Busan & http://www.busan.com/view/busan/view.php?code=20170911000026 \\
\hline 11 & 444-11 Suyeong-dong, Suyeong-gu, Busan & http://www.busan.com/view/busan/view.php?code=20170912000310 \\
\hline 12 & 154-1 Geumsa-dong, Geumjeong-gu, Busan & https://www.ytn.co.kr/_ln/0103_201709111340056508 \\
\hline 13 & 179-17 Millak-dong, Suyeong-gu, Busan & http://www.sporbiz.co.kr/news/articleView.html?idxno=144027 \\
\hline 14 & 604-5 Daeyeon-dong, Nam-gu, Busan & http://www.sportsseoul.com/news/read/550236 \\
\hline 15 & 117-1 Nampodong 6-ga, Jung-gu, Busan & https://news.v.daum.net/v/20170911094151647 \\
\hline
\end{tabular}


Table 4. Information of Non-Flood Sites

\begin{tabular}{c|l|l}
\hline No. & \multicolumn{1}{|c}{ Address } & \multicolumn{1}{c}{ Source } \\
\hline 1 & $907-28$ Jwacheon-dong, Dong-gu, Busan & https://blog.naver.com/dkdlqk37/221094356348 \\
\hline 2 & 1910 Geumgok-dong, Buk-gu, Busan & https://blog.naver.com/suyeoni09/221094616855 \\
\hline 3 & 1910 Geumgok-dong, Buk-gu, Busan & https://blog.naver.com/suyeoni09/221094616855 \\
\hline 4 & 63 Namcheon-dong, Suyeong-gu, Busan & https://blog.naver.com/fhqh145/221281084590 \\
\hline 5 & 203 Namcheon-dong, Suyeong-gu, Busan & https://blog.naver.com/vgomugomv/221095994114 \\
\hline 6 & $24-2$ Changseondong 2-ga, Jung-gu, Busa & https://blog.naver.com/fhqh145/221281084590 \\
\hline 7 & 17-1 Nampodong 2-ga, Jung-gu, Busan & https://blog.naver.com/s_martsun/221094612631 \\
\hline 8 & 1-2 Gwangbokdong 2-ga, Jung-gu, Busan & https://blog.naver.com/fhqh145/221281084590 \\
\hline 9 & $44-1$ Gwangbokdong 2-ga, Jung-gu, Busan & https://blog.naver.com/jhjsm/221094556743 \\
\hline
\end{tabular}


